\title{
Bio-Diesel Production from Waste Cooking Oil Via Acids Catalysis and Its Blends with Diesel
}

\author{
Dinesh S. Nichat ${ }^{*}$ and D.B.Shelke
}

Department of Mechanical Engineering, D.Y.Patil School of Engineering Academy,Talegaon (Ambi),Savitribai Phule Pune University, Ganeshkhind Pune-411007 Maharashtra, India

Accepted 15 June 2016, Available online 20 June 2016, Special Issue-5 (June 2016)

\begin{abstract}
Bio diesel is renewable source of energy, non-degradable, cleaner and efficient fuel for IC Engines. Conventionally it is produced by the alkali as a catalysis but due to more FFA contents in oils the Acid catalysis method is becoming popular for researchers. In this research work the productivity of different acids are evaluated for different concentrations of Acids, methanol, catalysts for constant temperature and time is to measure. The optimum combination Via Hydrochloric Acid and methanol /pretreated soybean oil, Acid concentration and time wise are calculated 0.16, 1\% and 28 min.which gives yield up to $81 \%$ which meets ASTM fuel requirements. The optimum combination via nitric Acid for methanol and soybean as a pretreated oil, Acid concentration and Time wise is 0.20 , $1.25 \%$ and 50 min. which gives yield up to $92.734 \%$ which meets ASTM fuel requirements. Optimum combination via sulfuric acid for methanol /Pretreated oil, Acid concentration and Time wise is $0.20,1.5 \%$ and 24 min, which gives yield up to $99.009 \%$ which meets ASTM fuel requirement.
\end{abstract}

Keywords: Biodiesel, Acid Catalyst, Transesterification

\section{Introduction}

Exploring renewable energy sources is the need of present fuel scenario; the petro-fuels are vanishing more rapidly to meet heavy demands of today's population. The Bio-fuels looks attractive and inviting source in this situation. Bio-diesel as a fuel of this category are more environmental benefits as a cleaner fuel and reduces emissions by $85 \%$ compare to the petrol-diesel. Combustion of bio-diesel as a fuel in diesel engine is more proper than gasoline and diesel with less emission of carbon monoxide, particulate matter and toxic chemicals (Ravi PV 2006).

Bio-diesel is the product of the process known as a 'stratification' in which Triglycerides from soybean oil reacts with alcohol under action of certain catalysts at specific constant temperature for specific time interval to produce bio-diesel as a result. Bio-diesel can be used in internal-combustion engine as a fuel application solely or blending with petrol-diesel. (Knothe G, Dunn RO, Bagby MO 1997). According to Literature review, its blends show good performance characteristics on diesel engine. Their blend improves properties like Lubricity and stability etc.

Lots of benefits of using biodiesel as a fuel it is renewable source, burns cleaner than petrol-diesel and compatible with petrol-diesel. Bio-diesel can be

*Corresponding author: Dinesh S. Nichat produced through many techniques including acid \& base catalysis, enzymatic conversion, solid catalysis, non-catalytic conversion and super-critical methanolysis. Enzymatic conversions are expensive and unable to provide requirements of ASTM diesel fuel specification, For Solid catalysis High pressure and temperature arrangements are required also for noncatalytic conversion are required large set-up of experimental and extreme operation conditions, so only base and acid catalysis are simple, easy and feasible techniques to local researchers out of which when free fatty acid contents are more than 5\% then there will more soap formation and wastage of base catalyst so it is unfavorable in such cases so remaining acid catalysis is used for biodiesel production when FFA content are more than 5\% in feed stock oil. This research paper is related to bio-diesel production from acid catalysis in which production rate of different acids is calculated. The Acids uses for this study are of AR (Analytical Reagent) quality including Hydrochloric acid, Nitric Acid and Sulfuric Acid

\section{Experimental}

A) Chemicals: All the chemical used are of Analytical Reagent (AR) quality which includes use of conc. hydrochloric acid (HCL), conc. nitric acids (HNO3), conc. sulphuric acids (H2SO4), sodium hydroxide pallets, Methanol etc. 


\section{B) Properties of used oil}

Oil PH: - $50 \mathrm{ml}$ beaker is used in which $2 \mathrm{gm}$ of sample of soybean oil is poured and $30 \mathrm{ml}$ distilled water added in it and stirred slowly. Then it is cooled up to 25 deg centigrade in water bath. The HP electrodes are dipped into solution and $\mathrm{PH}$ value measured from digital meter after stability.

Oil Viscosity:-It's viscosity measured by redwood visco-meter consist of steel two steel container, one is outer and other is inner. The diameter of outer container is larger than inner, and there having an empty space between the two. The empty space contains hot water which surrounded the inner container containing soybean oil in that. The water is heated by heating coil. The oil gain heat from surrounding hot water by convection. The oil container have very small hole at the bottom so that oil dropped through that hole. As we got required temperature on the temp. indicator, the small diam. rod removed to allowed the oil fall down in volume measuring flask. It required to measure that how much time taken by oil to fill $50 \mathrm{ml}$ in volume measuring flask. And viscosity calculated from the following constants and formula.

Viscosity $=\mathrm{A} * \mathrm{t}-\mathrm{B} / \mathrm{t}$

Where, $A=0.26, B=17, t=$ time

\section{C) Preparation of oil for biodiesel production}

The soybean oil is filtered to remove any impurity, foreign particle and debris present. The oil is heated at $100 \mathrm{deg}$ centigrade for $30 \mathrm{~min}$ to remove water and improve reactivity of oil. The amount of water should be less than $0.04 \%$ (wt \%). Then only the standard limit of water content is fulfilled. Water is very dangerous for acid catalysis it may disturb or even stop the bio-diesel production.

\section{D) Preparation of NA-O-CH3 for biodiesel production}

Silica Granule is used to dry the methanol and finally it is deep freeze. The potassium hydroxide (AR) surface is cleaned by steel knife and its weight is measured quickly. Then $\mathrm{KOH}$ is dipped in $100 \mathrm{ml}$ methanol containing beaker. The 'The magnetic rotor machine' is used to completely dissolve the $\mathrm{KOH}$ in methanol to form NA-O-CH3 solution in desired concentration. The stirring is done up to $15-20 \mathrm{~min}$ to form more homogeneous solution.

\section{E) Complete Protocol for Bio-diesel Production}

Initially the raw waste soybean coo king oil is heated up to 60 deg centigrade which improves the reactivity of oil and gives better results. Then the soybean oil is pretreated to reduce FFA content by treated it one by one with strong Acids e.g. HCL, HNO3, $\mathrm{H} 2 \mathrm{SO} 4$ etc these solution is heated and stirred vigorously at constant temperature of $70 \mathrm{deg}$ centigrade for 60 minutes for maintaining the constant temperature water bath is used and mechanical stirrer used for stirring.
Then the PH of pretreated oil is check which is must be 6 to 7 if not then the heating time of solution is extended. The PH is checked by $\mathrm{PH}$ analyzer by simply inserting PH analyzer probes in solution. The digital meter gives the reading of $\mathrm{PH}$. Pretreated oil is ready to use now.

The Centrifuging machine is used to remove the FFA from raw oil. The centrifuging machine is operated at 5200 RPM for 20 Minutes. The FFA level formed at upper portion which can easily remove. These is pioneering step for researchers working on bio diesels. The lower portion now be used for bio-diesel production.

Potassium Hydroxide pallets is added in Methanol and stirred vigorously for specific time to form sodium Methoxide. The Magnetic Rotor Machine is used for these purpose in which magnetic rotor is immersed in methanol contained beaker the machine frequently changes magnetic field which tends to rotate the magnetic rotor which then stirred the mixture vigorously.

These produced Sodium Methoxide is treated with Pretreated oil which contain less FFA contents e.g.by alkali catalysis method at constant temperature of 60 deg centigrade and stirred vigorously in water bath by mechanical stirrer. Generally, the bio-diesel formation starts from first 20 min then bio-diesel samples taken for testing after each five min onward to analyze the properties checked quality and meet ASTM fuel requirements. Then the best samples are chosen on the basis of properties obtained through empirical analysis.

The Centrifuging machine used finally to remove glycerin and if any catalysts impurity and foreign particles are presents. The test is taken one by one for following Acids HCL, HNO3, H2SO4. the found result are as follows

\section{Results}

\section{A) Biodiesel Production via HCL Acid}

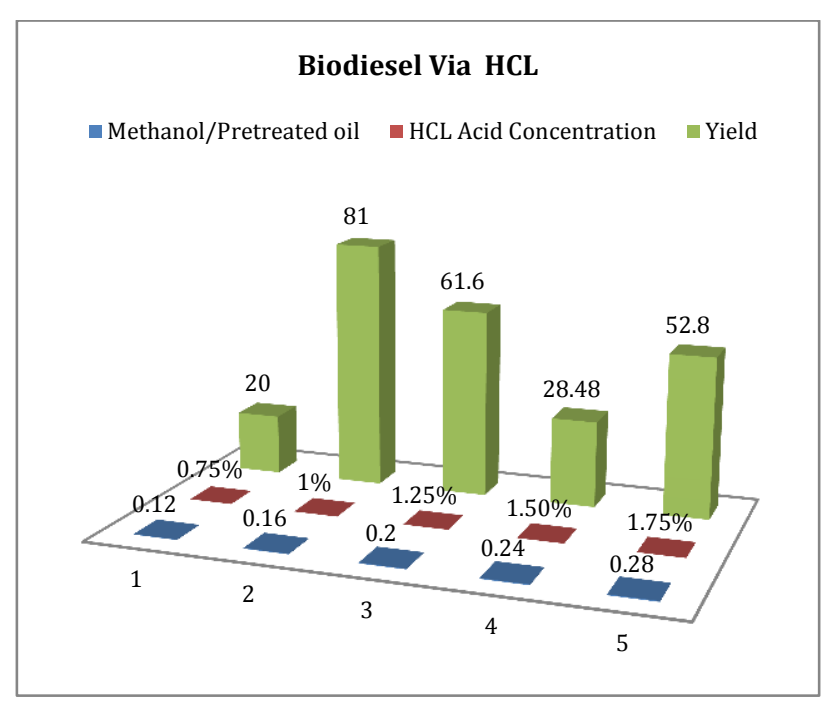

Fig.1 Biodiesel Processes Via HCL 
When HCL is used in different proportions and the results are studied is observed that Biodiesel (BD) is not formed up to $25 \mathrm{~min}$ and if we continue heating so after say 45 min unacceptable and viscous BD formed. The found best combination is Methanol /Pretreated oil, Acid concentration and Time wise is $0.16,1 \%$ and 28 min. which gives yield up to $81 \%$ which meets ASTM Fuel requirements.Fig.1shows the optimum combination while Fig. 2 shows the Glycerin (Wt\%) of Biodiesel process. Fig concludes that the sample 2 gives High yield with Low glycerin formation

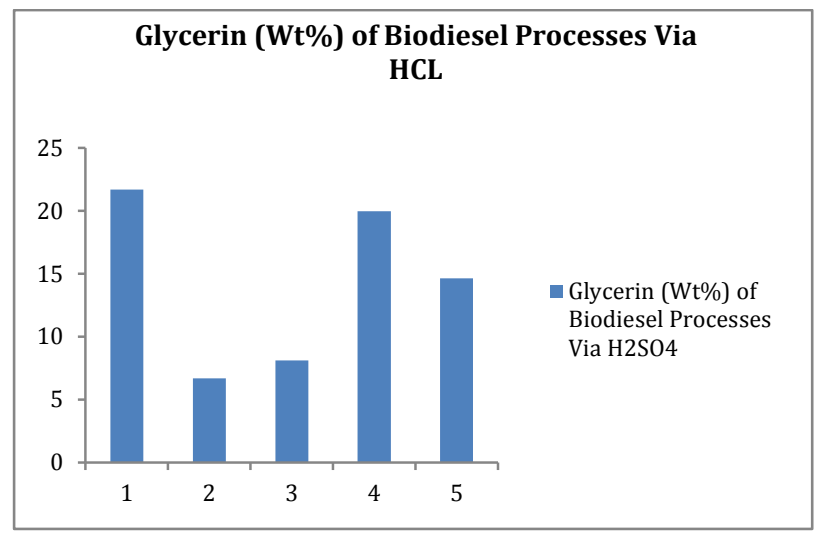

Fig.2 Glycerin (Wt\%) of Biodiesel Processes Via HCL

B) Biodiesel Production via HNO3 Acid

When HNO3 is used in different proportions and the results are studied is observed that Biodiesel (BD) is formed after $40 \mathrm{~min}$ and if we continue heating and increased Acid concentration BD form faster but unacceptable and viscous BD formed. The found best The optimum combination Via Nitric Acid for Methanol /Pretreated oil, Acid concentration and Time wise is $0.20,1.25 \%$ and 50 min.which gives yield up to 92.734\% which meets ASTM Fuel requirements..Fig.3 shows the optimum combination while Fig.4 shows the Glycerin (Wt \%) of Biodiesel process. Fig concludes that the sample ' 3 ' gives High yield with Low glycerin formation.

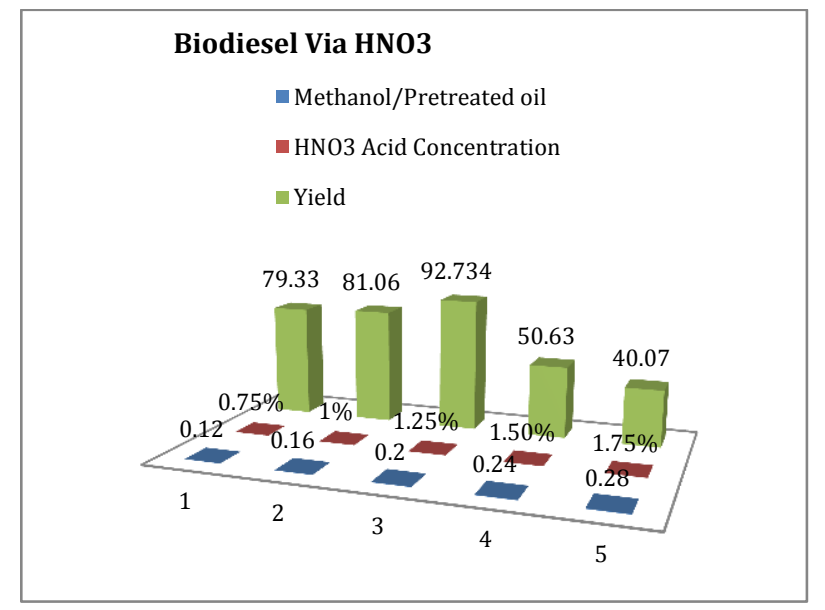

Fig.3 Biodiesel processes Via HNO3

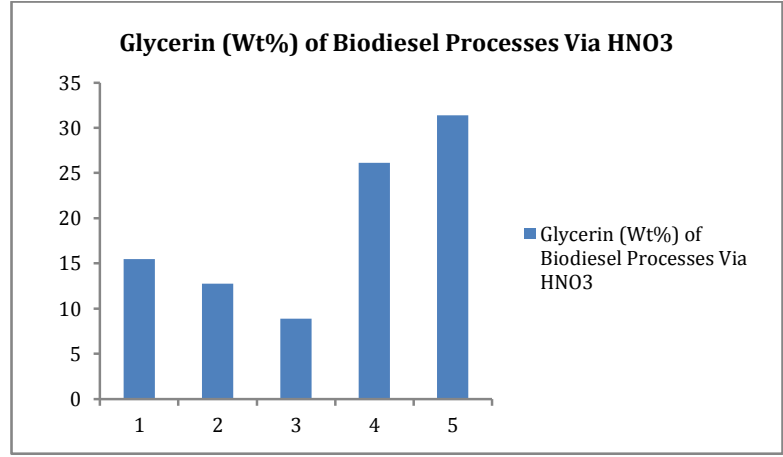

Fig.4 Glycerin (Wt\%) of Biodiesel Processes Via HNO3

C) Biodiesel Production via H2SO4 Acid

When $\mathrm{H} 2 \mathrm{SO} 4$ is used in different proportions and the results are studied it is observed that Biodiesel (BD) is formed after $20 \mathrm{~min}$ and if we continue heating and increased Acid concentration BD form faster but unacceptable and viscous BD formed. The found best optimum combination Via Sulfuric Acid for Methanol /Pretreated oil, Acid concentration and Time wise is $0.20,1.5 \%$ and 24 min.which gives yield up to $99.009 \%$ which meets ASTM Fuel requirements.Fig3.3 (a) shows the optimum combination while Fig3.3 (b) shows the Glycerin (Wt \%) of Biodiesel process. Fig concludes that the sample ' 3 ' gives High yield with Low glycerin formation.

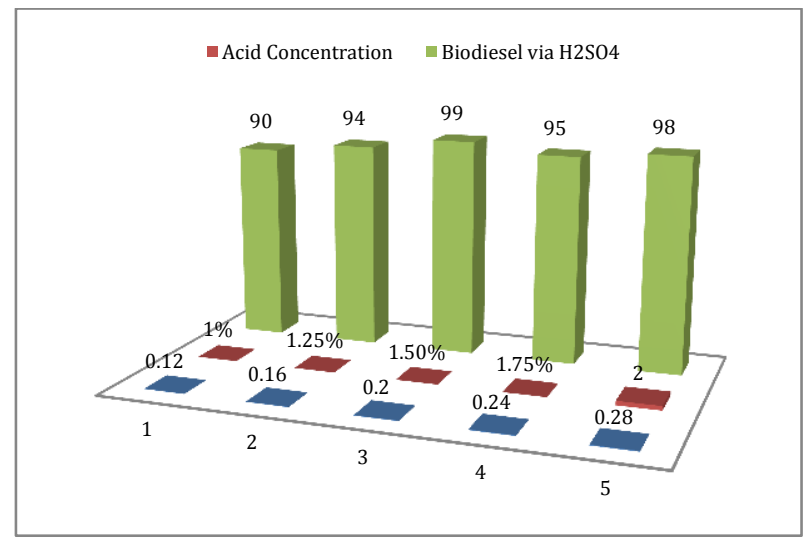

Fig.5 Biodiesel processes Via H2SO4

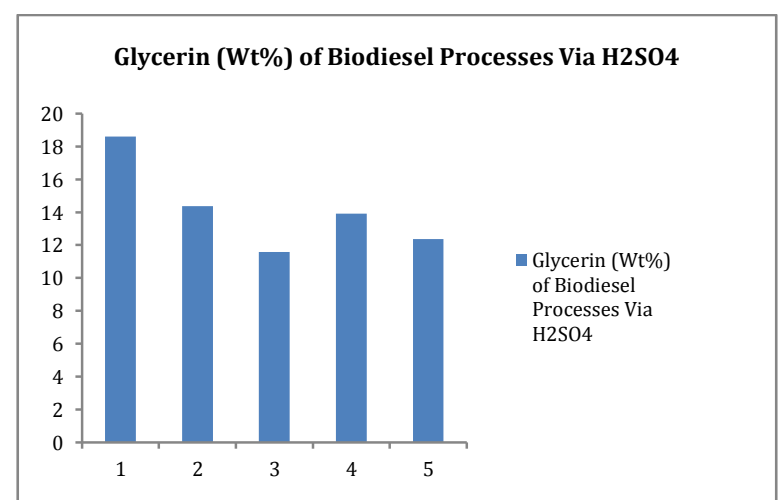

Fig.6 Glycerin (Wt\%) of Biodiesel Processes Via H2SO4 
Table 1 Properties of Biodiesel Produced Via different acids

\begin{tabular}{|c|c|c|c|c|c|c|c|c|c|c|c|c|}
\hline$\dot{z}$ & 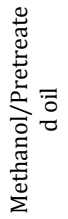 & 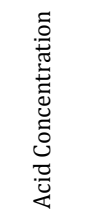 & छ̊ છ & $\stackrel{\mathscr{\Xi}}{\Xi}$ & $\stackrel{0}{\stackrel{0}{e}}$ & 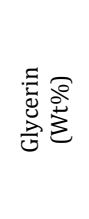 & 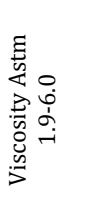 & 3 & $\begin{array}{l}\stackrel{+}{\Xi} \\
\stackrel{0}{a} \\
\frac{1}{5} \\
\frac{\pi}{I}\end{array}$ & $\begin{array}{l}\stackrel{\Xi}{0} \\
\stackrel{0}{0} \\
\stackrel{0}{0}\end{array}$ & $\underset{E}{Z}$ & 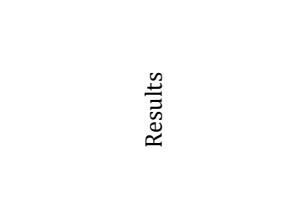 \\
\hline \multicolumn{12}{|c|}{ HCL } & \\
\hline 1 & 0.12 & $.75 \%$ & 60 & 35 & 20 & 21.67 & 7.11 & 41122 & 167 & 173 & $\begin{array}{c}0.512 \\
2\end{array}$ & $\begin{array}{l}\text { For time up to } 25 \text { min NO } \\
\text { formation of BD After } 45 \\
\text { min more viscous \& } \\
\text { unacceptable BD form. }\end{array}$ \\
\hline 2 & 0.16 & $1 \%$ & 60 & 28 & 81 & 6.67 & 5.08 & 42800 & 148 & 157 & $\begin{array}{c}0.512 \\
5\end{array}$ & $\begin{array}{l}\text { BD form after } 20 \text { min and } \\
\text { mostly acceptable up to } 40 \\
\text { after more viscous BD form. }\end{array}$ \\
\hline 3 & 0.20 & $1.25 \%$ & 60 & 68 & 61.6 & 8.11 & 9.54 & 38522 & 159 & 167 & $\begin{array}{c}0.563 \\
6\end{array}$ & $\begin{array}{l}\text { BD form in some minutes } \\
\text { but viscous and } \\
\text { unacceptable \& heating } \\
\text { time hence Increased. }\end{array}$ \\
\hline 4 & 0.24 & $1.50 \%$ & 60 & 55 & 28.48 & 19.96 & 10.45 & 39855 & 167 & 173 & $\begin{array}{c}0.598 \\
9\end{array}$ & $\begin{array}{l}\text { BD form in some minutes } \\
\text { but viscous and } \\
\text { unacceptable. }\end{array}$ \\
\hline 5 & 0.28 & $1.75 \%$ & 60 & 43 & 52.8 & 14.62 & 12.33 & 36555 & 168 & 175 & $\begin{array}{c}0.612 \\
4\end{array}$ & $\begin{array}{c}\text { BD form in some minutes } \\
\text { but viscous and } \\
\text { unacceptable. }\end{array}$ \\
\hline \multicolumn{13}{|c|}{ HNO3 } \\
\hline 6 & 0.12 & $0.75 \%$ & 60 & 90 & 79.33 & 15.48 & 3.98 & 42556 & 162 & 171 & $\begin{array}{c}0.417 \\
2\end{array}$ & $\begin{array}{l}\text { BD Form after } 70 \text { min less } \\
\text { viscous but not meet ASTM. }\end{array}$ \\
\hline 7 & 0.16 & $1 \%$ & 60 & 62 & 81.06 & 12.76 & 4.12 & 40235 & 165 & 173 & $\begin{array}{c}0.489 \\
8\end{array}$ & $\begin{array}{l}\text { BD Form after } 55 \text { min less } \\
\text { viscous but not meet ASTM. }\end{array}$ \\
\hline 8 & 0.20 & $1.25 \%$ & 60 & 50 & 92.734 & 8.89 & 4.59 & 41222 & 157 & 152 & $\begin{array}{c}0.501 \\
2\end{array}$ & $\begin{array}{l}\text { BD Form after } 40 \text { min less } \\
\text { viscous And meets ASTM. }\end{array}$ \\
\hline 9 & 0.24 & $1.50 \%$ & 60 & 45 & 50.63 & 26.142 & 6.98 & 41235 & 171 & 180 & $\begin{array}{c}0.598 \\
6\end{array}$ & $\begin{array}{c}\text { BD Form after } 20 \text { min more } \\
\text { viscous. }\end{array}$ \\
\hline 10 & 0.28 & $1.75 \%$ & 60 & 36 & 40.07 & 31.39 & 7.33 & 42512 & 173 & 181 & $\begin{array}{c}0.612 \\
3\end{array}$ & $\begin{array}{l}\text { BD Form immediately but } \\
\text { more viscous. }\end{array}$ \\
\hline \multicolumn{13}{|c|}{$\mathrm{H} 2 \mathrm{SO} 4$} \\
\hline 11 & 0.12 & $1 \%$ & 60 & 45 & 90.848 & 18.60 & 5.68 & 42536 & 159 & 168 & $\begin{array}{c}0.512 \\
4\end{array}$ & $\begin{array}{l}\text { BD Form after } 20 \text { min but } \\
\text { poor quality up to } 40 \text { Above } \\
\text { good up to } 90 \text { min and then } \\
\text { viscous. }\end{array}$ \\
\hline 12 & 0.16 & $1.25 \%$ & 60 & 40 & 94.723 & 14.36 & 6.25 & 41988 & 168 & 175 & $\begin{array}{c}0.523 \\
5\end{array}$ & $\begin{array}{l}\text { BD Form after } 15 \text { min but } \\
\text { poor quality. }\end{array}$ \\
\hline 13 & 0.20 & $1.50 \%$ & 60 & 24 & 99.009 & 11.58 & 3.99 & 40235 & 154 & 161 & $\begin{array}{c}0.535 \\
0\end{array}$ & $\begin{array}{c}\text { BD form immediately after } \\
40 \text { min viscosity increases } \\
\text { drastically. }\end{array}$ \\
\hline 14 & 0.24 & $1.75 \%$ & 60 & 65 & 95.0628 & 13.92 & 6.11 & 45889 & 171 & 178 & $\begin{array}{c}0.598 \\
1\end{array}$ & $\begin{array}{c}\text { BD form immediately but } \\
\text { unacceptable. }\end{array}$ \\
\hline 15 & 0.28 & 2.00 & 60 & 88 & 98.174 & 12.36 & 7.14 & 43566 & 169 & 176 & $\begin{array}{c}0.631 \\
5\end{array}$ & $\begin{array}{l}\text { BD form immediately but } \\
\text { unacceptable. }\end{array}$ \\
\hline
\end{tabular}

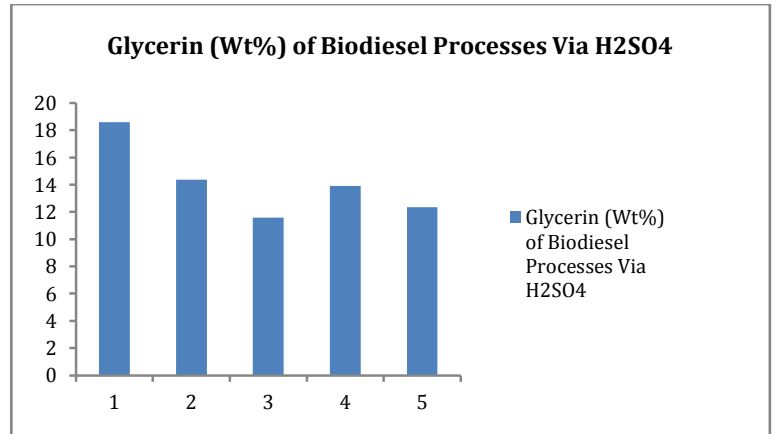

Fig.6 Glycerin (Wt\%) of Biodiesel Processes Via H2SO4

D) Biodiesel Production Comparison for different Acids.

The Biodiesel Production Via H2SO4 gives High yield than other Acids. The properties of $\mathrm{BD}$ via $\mathrm{H} 2 \mathrm{SO} 4$ is good but the BD produced via HCL also shows good results in consideration through yield wise and properties wise which is achievement of the experimentation done.

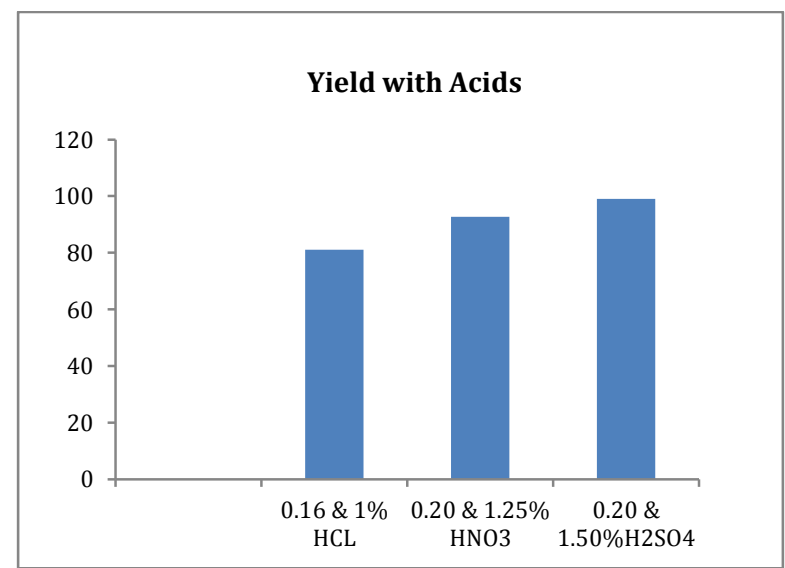

Fig.7: Yields with Different Acid 


\section{Experimental fuels}

The main fuels used are diesel as baseline fuel, Biodiesel Produced using Sulfuric Acid (BD-1), Biodiesel Produced using Hydrochloric Acid (BD-2) \& Biodiesel Produced using Nitric Acid (BD-3) The various Physio-Chemical and other properties of fuels is given in following table no 2 .

Table 2 Properties of fuels

\begin{tabular}{|c|c|c|c|c|c|}
\hline S no & Properties & Diesel & BD1 & BD2 & BD3 \\
\hline 1 & Density (Kg/m3) & 823 & 845 & 850 & 836 \\
\hline 2 & $\begin{array}{c}\text { Calorific value } \\
\text { (MJ } / \mathrm{kg})\end{array}$ & 43 & 40.90 & 40.30 & 38.52 \\
\hline 3 & $\begin{array}{c}\text { Viscosity @ } 40^{\circ} \mathrm{C} \\
(\mathrm{cst})\end{array}$ & 3.9 & 5.2 & 5.78 & 4.99 \\
\hline 4 & Flash point $\left({ }^{\circ} \mathrm{C}\right)$ & 72 & 120 & 130 & 135 \\
\hline 5 & Fire Point & 78 & 126 & 137 & 141 \\
\hline 6 & TAN & 0.1750 & 0.2125 & 0.3585 & 0.4510 \\
\hline
\end{tabular}

\section{Blend preparation}

The different blends of diesel and Biodiesel were prepared on volume basis. The blends were prepared in blender. The various blends prepared are given as follows. The three Blends are prepared from each Acid Biodiesels. We have BD Via Sulfuric Acid (BD1), BD Via Hydrochloric Acid (BD2) \& BD Via Nitric Acid (BD3). Total Nine Blends are Prepared.

\section{Blends of Diesel \& BD-1}

1) B20 (80\% diesel $20 \%$ BD-1)

2) $\mathrm{B} 30(70 \%$ diesel $30 \% \mathrm{BD}-1)$

3) B40 (60\% diesel $40 \%$ BD-1)

Blends of Diesel \& BD-2

4) B 20 ( $80 \%$ diesel $20 \%$ BD-2)

5) $\mathrm{B} 30$ (70\% diesel $30 \% \mathrm{BD}-2)$

6) B40 (60\% diesel $40 \%$ BD-2)

Blends of Diesel \& BD-3

7) B 20 (80\% diesel $20 \%$ BD-3)

8) B 30 (70\% diesel $30 \%$ BD-3)

9) B40 (60\% diesel $40 \%$ BD-3)

Table 3 Properties of various blends

\begin{tabular}{|c|c|c|c|c|c|}
\hline SN & $\begin{array}{c}\text { Blen } \\
\text { ds }\end{array}$ & $\begin{array}{c}\text { Density } \\
(\mathrm{Kg} / \mathrm{m} 3)\end{array}$ & $\begin{array}{c}\text { Calorific } \\
\text { value } \\
(\mathrm{M} / \mathrm{kg})\end{array}$ & $\begin{array}{c}\text { Viscosity@40 } \\
\text { (cst) }\end{array}$ & $\begin{array}{c}\text { Flash } \\
\text { point } \\
\left({ }^{\circ} \mathrm{C}\right)\end{array}$ \\
\hline \multicolumn{7}{|c|}{ Blends of BD Via Sulfuric Acid (BD1) } \\
\hline 1 & B20 & 825 & 42.600 & 4.16 & 81 \\
\hline 2 & B30 & 829 & 42.380 & 4.30 & 86 \\
\hline 3 & B40 & 833 & 42.150 & 4.45 & 92 \\
\hline \multicolumn{7}{|c|}{ Blends of BD Via Hydrochloric Acid (BD2) } \\
\hline 4 & B20 & 827 & 42.500 & 4.22 & 83 \\
\hline 5 & B30 & 832 & 42.300 & 4.35 & 88 \\
\hline 6 & B40 & 835 & 41.150 & 4.65 & 96 \\
\hline \multicolumn{7}{|c|}{ Blends of BD Via Nitric Acid (BD3) } \\
\hline 7 & B20 & 831 & 41.900 & 4.12 & 85 \\
\hline 8 & B30 & 835 & 41.656 & 4.23 & 91 \\
\hline 9 & B40 & 840 & 40.208 & 4.60 & 98 \\
\hline
\end{tabular}

\section{Conclusions}

1) The optimum combination Via Hydrochloric Acid for Methanol /Pretreated oil, Acid concentration and time wise is $0.16,1 \%$ and 28 min.which gives yield up to $81 \%$ which meets ASTM Fuel requirements.

2) The optimum combination Via Nitric Acid for Methanol /Pretreated oil, Acid concentration and Time wise is $0.20,1.25 \%$ and 50 min.which gives yield up to $92.734 \%$ which meets ASTM Fuel requirements.

3) The optimum combination Via Sulfuric Acid for Methanol /Pretreated oil, Acid concentration and time wise is $0.20,1.5 \%$ and 24 min.which gives yield up to $99.009 \%$ which meets ASTM Fuel requirements.

4) The productivity of sulfuric acid is highest the Nitric Acid is moderate while Hydrochloric acid is lowest yield wise. The biodiesel produced via Hydrochloric acid has good fuel properties than nitric Acids.

\section{References}

Sastry GSR, Krishna Murthy ASR, Ravi Prasad P, Bhuvaneswari K, Ravi PV.(2006) Identification and determination of bio-diesel in Diesel Energy Sources Part A;28:1337-42.

Knothe G, Dunn RO, Bagby MO (1997). Biodiesel: the use of vegetable oils and their derivatives as alternative Diesel fuels. Am Chem Soc Symp Series; 666:172-208.

Hama S, Yamani H, Kaieda M, Oda M, Kondo A, Fukuda H (2004). Effect of fatty acid membrane composition on whole-cell biocatalysts for biodiesel-fuel production. Biochem Eng J; 21:15560.

Oda M, Kaieda M, Hama S, Yamaji H, Kondo A, Izumoto E, et al.(2004) Facilitatory effect of immobilized lipase-producing Rhizopus oryzae cells on acyl migration in biodiesel-fuel production. Biochem Eng J; 23:45-51.

Shieh C-J,Liao H-F, LeeC-C.(2003) Optimization of lipase-catalyzed biodiesel by response surface methodology.Biores Technol;88:103-6.

Noureddini H, Gao X, Philkana RS. (2005) Immobilized pseudomonas cepacia lipase for biodiesel fuel production from soybean oil. Biores Technol; 96:769-77

Demirbas A (2003). Biodiesel fuels from vegetable oils via catalytic and noncatalytic supercritical alcohol transesterifications and other methods: a survey. Energy Convers Manage; 44:2093-109.

Noureddini H, Gao X, Philkana RS. (2005) Immobilized pseudomonas cepacia lipase for biodiesel fuel production from soybean oil. Biores Technol; 96:769-77.

Barnwal BK, Sharma MP. (2005) Prospects of Biodiesel production from vegetable oils in India. Renew Sust Energy Rev;9(4):36378.

Srivastava A, Prasad R. (2000) Triglycerides-based diesel fuels. Renew Sust Energy Rev; 4:111-33.

Ma F, Hanna MA. (1999) Biodiesel production: a review. Bio resource Technology; 70:1-15

Fukuda H, Kondo A, Noda H (2001). Biodiesel fuel production by transesterification of oils. J Biosci Bioeng ; 92(5):405-16

Barnwal BK, Sharma MP. (2005) Prospects of Biodiesel production from vegetable oils in India. Renew Sust Energy Rev; 9(4):36378.

Y, Dube' MA, McLean DD, Kates M. (2003) Biodiesel production from waste cooking oil: 1. Process design and technological assessment. Bioresource Technol; 89:1-16.

Freedman B, Pryde EH, Mounts TL (1984). Variables affecting the yields of fatty esters from transesterifiedvegetable oils. JAOCS;61(10):1638-43.

Noureddini H, Zhu D (1997). Kinetics of transesterification of soybean oil. JAOCS;74(11):1457-63.

Debirmas A (1999).Fatty and resin acid recovered from spruce wood by supercritical acetone extraction. Holzforschung,45:337-9 